\title{
Cholinergic Stimulation with Pyridostigmine, Hemodynamic and Echocardiographic Analysis in Healthy Subjects
}

\author{
Paulo Vasconcellos de Pontes, Bianca Gouveia Bastos, Luiz José Martins Romêo $F^{\circ}$, \\ Evandro Tinoco Mesquita, Antonio Claudio Lucas da Nóbrega
}

Niterói, RJ - Brazil

\begin{abstract}
Objective - Growing evidence suggests that sudden death after an acute myocardial infarction (AMI) correlates with autonomic nervous system imbalance. Parasympathomimetic drugs have been tested to reverse these changes. However, their effects on ventricular function need specific evaluation. Our objective was to analyze pyridostigmine's (PYR) effect on hemodynamic and echocardiographic variables of ventricular function.
\end{abstract}

Methods - Twenty healthy volunteers underwent Doppler echocardiographic evaluations, blood pressure $(B P)$, and heart rate (HR) assessment at rest, before and 120 min after ingestion of $30 \mathrm{mg} P Y R$ or placebo, according to a double-blind, placebo-controlled, crossed and randomized protocol, on different days.

Results - PYR was well tolerated and did not cause alterations in $B P$ or in ventricular systolic function. $A$ reduction in HR of $10.9 \pm 1.3 \%$ occurred $(p<0,00001)$. There was an $A$ wave reduction in the mitral flow $(p<0.01)$ and an $E / A$ ratio increase $(p<0.001)$ without changes in the other diastolic function parameters ( $p>0.05)$.

Conclusion - PYR reduces HR and increases E/A ratio, without hemodynamic impairment or ventricular function change.

Key-words: pyridostigmine, autonomic nervous system, coronary arterial disease
Hospital Universitário Antônio Pedro - UFF

Mailing address: Paulo Vasconcellos de Pontes - Rua 8 de Dezembro, 514/102 20550-200 - Rio de Janeiro, RJ - Brazil
During the past decades, great progress has been made in the treatment of coronary heart disease primarily because of the evolution of the therapeutic arsenal. $\beta$ blockers, for instance, have been shown in some studies to cause a significant reduction in mortality, mainly through a reduction in sudden death ${ }^{1-3}$. These effects are due to a decrease in myocardial $\mathrm{O}_{2}$ consumption and additionally to the blockade of postinfarction adrenergic hyperactivity ${ }^{4}$. Recent studies have identified subgroups under greater risk of sudden death through the use of high resolution electrocardiography, continuous electrocardiographic monitoring and baroreflex sensitivity (BRS) analysis in order to stratify postinfarction risk ${ }^{5-8}$. In addition to the dysautonomia due to adrenergic hyperactivity, a concomitant vagal hypoactivity may be present, expressed by reduction in RR variability (RRV) and BRS ${ }^{9-10}$. From its initial correlation with sudden death ${ }^{11}$, and after experimental ${ }^{12}$ and clinical ${ }^{13}$ evidence of its prognostic value became available, vagal hypoactivity has come to be considered an independent risk factor for postinfarction sudden death ${ }^{7,14,15}$. As a result, therefore, interest has arisen in the therapeutic action of medicines modulating the parasympathetic system, in particular, effects on the action of acetylcholine (Ach). In 1993, four groups ${ }^{16-19}$ published the first studies on the effects of scopolamine, a cholinomimetic agent in low doses, on the vagal tonus of postinfarction patients. All the studies showed vagomimetic effect through the reduction of the heart rate (HR) and increase of the VRR and/or BRS, but the possible protective effect of scopolamine on morbidity and mortality remains to be evaluated. Despite the positive results achieved, scopolamine is inconvenient because its cholinergic agonist action is present only in low doses and the opposite (blocking) effect occurs in greater doses ${ }^{20}$. This fact makes it difficult to determine the right dose in patients needing it, because it may cause a potentially deleterious cholinergic blockade. Moreover, no scopolamine studies in postinfarction patients have adequately reported its effects on ventricular systolic and diastolic functions, which are fundamental variables in the coronary disease patient population. 
Pyridostigmine (PYR) seems to be more suitable for use in postinfarction patients. As a reversible acetylcholinesterase (AchE) inhibitor, atropine being its antidote, PYR has a dose-dependent cholinomimetic action ${ }^{21}$, allowing dose setting according to individual patient response. In addition to the large amount of experience accumulated by its use in myasthenia gravis (MG) and prophylaxis of intoxication by organophosphates (chemical war weapons: sarin, soman and tabun) ${ }^{22-25}$, PYR does not penetrate the central nervous system, may be administered by oral via and has few side effects ${ }^{21}$, which are all great advantages in comparison with scopolamine. In Brazil, Nóbrega et $\mathrm{al}^{26}$, considering the potential of PYR use in postinfarction patients, has documented the reflex and rest responses of HR to cholinergic stimulation produced by administering a single dose of PYR to healthy volunteers. Despite the theoretically negative inotropic effect of these agents being less intense, due to reduced ventricular vagal innervation, specific evaluation is necessary. The objective of this study was to evaluate PYR's effect on BP, HR, systolic and diastolic functions by Doppler echocardiography, and the drug tolerance in healthy individuals at rest.

\section{Methods}

Twenty healthy volunteers underwent fasting Doppler echocardiographic evaluations immediately before and $120 \mathrm{~min}$ after ingestion of $30 \mathrm{mg}$ PYR bromide or placebo, according to a double-blind, placebo-controlled, crossed and randomized protocol, on different randomly selected days, with a seven day minimum interval. We measured BP and HR (three times each) immediately after each evaluation. Thus, four value conditions were established (preplacebo, post-placebo, pre-PYR and post-PYR measures), each volunteer being his own control (crossed protocol). All volunteers were informed of the study objectives, methodology and risks, signing, thereafter, a formal written consent. We used the following inclusion criteria: normal physical examination, electrocardiogram and Doppler echocardiogram. Exclusion criteria were: a previous history of heart disease, diabetes mellitus, asthma or bronchitis, known hypersensitivity to PYR bromide, use of drugs with effects on the cardiovascular or autonomic nervous system (ANS) and pregnancy. The study was approved by UFF's Comitê de Ética da Pós-Graduação (Post-Graduation Ethics Committee).

Ninety-five percent of the group analyzed were volunteers involved in biomedical activities (university students, graduates, university teachers), $8(40 \%)$ were female, 17 $(85 \%)$ were white and $3(15 \%)$ were nonwhite, mean age was $25 \pm 5$ years, mean weight was $70 \pm 13 \mathrm{~kg}$, mean height was $1.7 \pm 0.1 \mathrm{~m}$, and mean body surface was $1.83 \pm 0.19 \mathrm{~m}^{2}$. The Doppler echocardiographic analysis was performed by only one observer, who did not know the applied condition (placebo or drug). An ATL Apogee CX200 was used with a $2.5 \mathrm{MHz}$ sectorial mechanical transducer and simultaneous electro-cardiographic record. Each volunteer's evaluation was immediately preceeded by a $10 \mathrm{~min}$ dorsal decubitus rest in the examination bed, aiming to attain a hemodynamic return to basal conditions.

An average of five measurements was obtained for each parameter. Ventricular diameter measurements were obtained a ccording to the standardization established at the Penn Convention ${ }^{27-29}$. The following parameters were obtained: ejection fraction $(\mathrm{EF})^{30}$, fractional shortening of the left ventricle $^{30}(\Delta D)$, cardiac index and output ${ }^{31}$, endsystolic stress and thickening ${ }^{32-35}$, isovolumic relaxation time ${ }^{36}$ (IVRT), velocity of the early filling of the mitral inflow ${ }^{36}(\mathrm{E})$, velocity of the late filling of the mitral inflow ${ }^{36}(\mathrm{~A}), \mathrm{E} / \mathrm{A} \mathrm{ratio}^{36}$, mitral deceleration time of the $E$ wave ${ }^{36}$ (DT), and left ventricle (LV) myocardial stiffness ${ }^{37}\left(\mathrm{~K}_{\mathrm{LV}}\right)$. BP, HR and Doppler echocardiographic evaluation data were analyzed using two-way ANOVA variance analysis for repeated measures. Whenever statistical significance was found, Tukey's procedure was used to compare and contrast differences in the mean values obtained. Moreover, for HR analysis, percent variations were obtained between pre- and post-values, in placebo and PYR conditions, which were compared using Student's $t$ test for paired measures. For all tests, the value $\mathrm{p}<0.05$ was considered significant.

\section{Results}

One volunteer developed myofasciculations and piloerection related to PYR, which was self-limited and did not need any sort of intervention. There were no hemodynamic changes or anything representing a risk to the subjects. One volunteer had an episode of self-limited and fugacious lipothymia, which he attributed to the prolonged fasting required for the procedure. At that time, he was in the PYR action peak, with a HR of $44 \mathrm{bpm}$ and $\mathrm{BP}$ of $100 \times 60 \mathrm{mmHg}$.

There was no statistically significant difference among the four study conditions for systolic and diastolic blood pressures. HR showed an average reduction of 7.1bpm post-PYR $(57.5 \mathrm{bpm} \pm 1.9 \mathrm{SE})$ compared with pre$\operatorname{PYR}(64.6 \mathrm{bpm} \pm 2.1 \mathrm{SE})$, which was found to be statistically significant ( $\mathrm{p}<0.05$-ANOVA) (fig. 1 ).

When HR was analyzed according to the respective control percent variation, placebo and PYR showed average reductions of $2.3 \% \pm 1.2 \mathrm{SE}$ and $10.9 \% \pm 1.3 \mathrm{SE}$, respectively (figs. 2 and 3). Student's paired $t$ test revealed the difference to be markedly statistically significant $(\mathrm{p}<0.00001)$.

There was no significant change in ventricular diameters and volumes or in ventricular systolic function indices, such as EF, $\Delta \mathrm{D}$, cardiac index and output. Endsystolic stress and thickening indices likewise remained unchanged. No statistically significant change in IVRT, DT and $\mathrm{K}_{\mathrm{LV}}$ occurred.

A significant reduction in the A wave post-PYR (fig. 4) occurred compared with the other conditions $(\mathrm{p}<0.001)$. E wave tended to increase, but its increase did not reach statistical significance. 


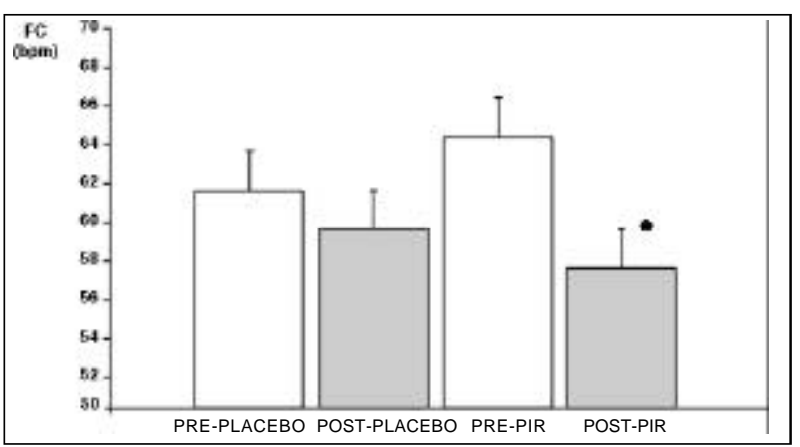

Fig. 1 - Means and standard errors of heart rate $\left({ }^{*} \mathrm{p}<0.05\right)$.

E/A ratio showed a significant increase post-PYR (fig. 5) compared with the other conditions $(\mathrm{p}<0.001)$.

Straight line regressions were determined from pre-/ post-placebo and pre-/post-PYR, correlating HR to A wave and $\mathrm{HR}$ to E/A ratio (fig. 6), aiming to identify A wave and E/ A ratio variations, regardless of the changes secondary to $H R$ reduction. It was demonstrated that, for any given $\mathrm{HR}$, the post-PYR condition has the smallest A wave and the largest E/A ratio among the four conditions. In addition to upper displacement, there is a greater slope in its straight line, indicating still greater E/A values for smaller HR values.

\section{Discussion}

The importance of HR reduction in coronary artery disease has been reported in studies that determined the effectiveness of $\beta$-blockers in reducing morbidity and mortality ${ }^{38}$. Also in congestive heart failure (CHF), HR was identified as an independent prognostic factor, reflecting abnormal sympathetic nervous system activation ${ }^{39}$. Additionally, ventricular function improvement in patients using amiodarone was ascribed to amiodarone-induced HR reduction ${ }^{40}$. Evidence exists that $\mathrm{HR}$ reduction might, by itself, improve ventricular function in this population ${ }^{41,42}$. On the other hand, several agents used in CHF treatment, by increasing EF and functional capacity, may not necessarily increase survival ${ }^{43-45}$.

PYR has arisen as a medicamentous treatment option in $\mathrm{HR}$ reduction. Its pharmacological profile seems attractive, when considering its use in CHF or coronary artery

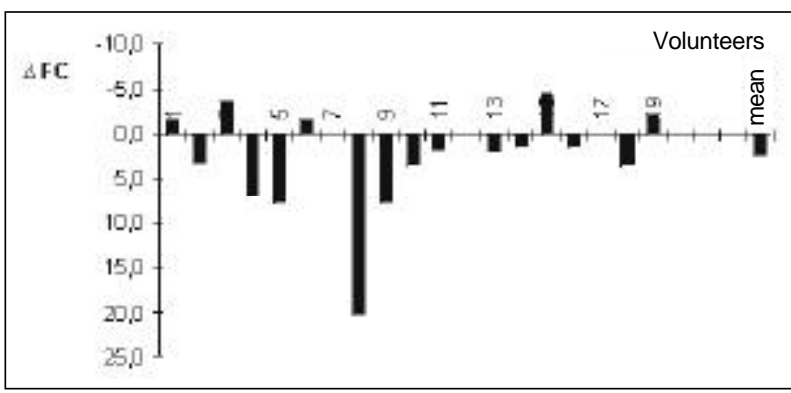

Fig. 2 - Percentage reduction of heart rate with placebo use compared to control $(* \mathrm{p}=\mathrm{NS})$. disease patients, in particular the absence of effects on ventricular systolic function and peripheral resistance. In addition, its action on the ANS has been broadly established from its use in MG patients, as well as its safety profile ${ }^{46}$. Its capability to promote improvements in the markers of dysautonomia in patients with heart diseases, still remains to be determined, as well as its impact on morbidity and mortality indices in this population. This study was a first approach in this direction, aiming to corroborate its safety profile with regards to hemodynamic and ventricular function variables.

The present study shows that PYR is well tolerated, and does not have severe side effects in the dose used, which corroborates the literature ${ }^{47-49}$. As in the study conducted by Nóbrega et $\mathrm{al}^{26}$, PYR caused HR reduction in subjects $(\mathrm{p}<0.05)$ - this is particularly true in the present study, where HR decreased in all subjects. Despite the significant HR reduction in the post-PYR condition, there was no corresponding change in cardiac index and output, probably due to a trend of stroke volume increase $(\mathrm{p}=\mathrm{NS})$. Similar hemodynamic behavior was shown in an experimental study in dogs ${ }^{50}$.

The A wave reduction was statistically significant $(\mathrm{p}<0.01)$. This reduction, associated with a nonsignificant trend of $E$ wave increase, resulted in a still greater increase in $\mathrm{E} / \mathrm{A}$ in the post-PYR condition ( $\mathrm{p}<0.001)$.

From interpreting PYR-induced mitral flow changes, we identified three mechanisms for E/A ratio increase: 1) improvement in ventricular relaxation, 2) secondary to HR reduction, and 3 ) secondary to a reduction in left atrial inotropism.

Although the mitral flow E/A ratio increase might indicate improvement in ventricular relaxation, other factors may also cause this effect. Indeed, the present study does not support the inference that PYR has an action on ventricular relaxation, because IVRT, DT or $\mathrm{K}_{\mathrm{LV}}$ changes did not occur. However, we have found a study ascribing to PYR an improvement in LV relaxation in hypertensive patients ${ }^{51}$.

Harrison et al ${ }^{52}$ have shown an inverse correlation between $\mathrm{HR}$ and E/A ratio in healthy subjects. One may, therefore, conclude that HR reduction with PYR has been responsible for the increase in the E/A ratio. However, $\mathrm{A}$

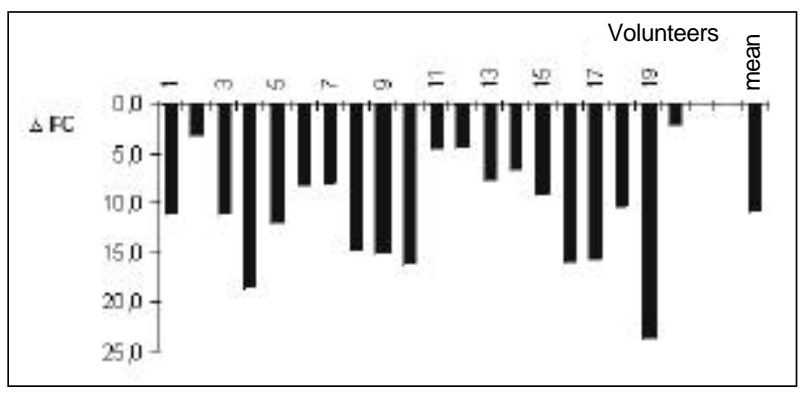

Fig. 3 - Percentage reduction of heart rate with PYR use compared to control $(* \mathrm{p}<0.00001)$. 


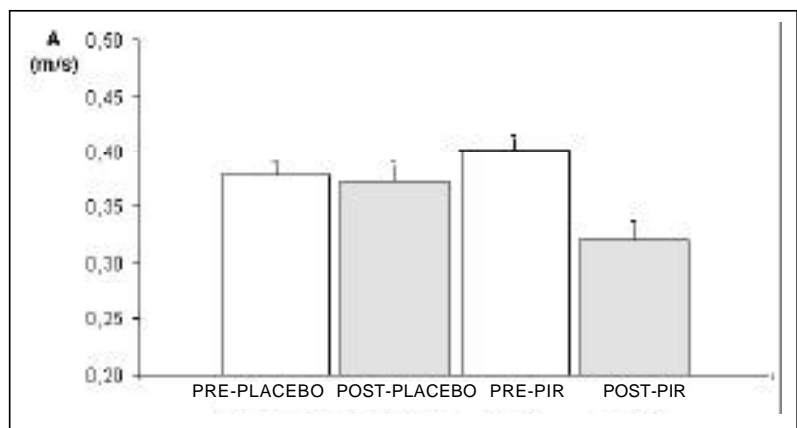

Fig. 4 - Means and standard errors of A wave $(* \mathrm{p}<0.01)$.

wave values were always lower in the post-PYR condition for any given $\mathrm{HR}$ value. These findings indicate that, in addition to the expected $\mathrm{A}$ wave and $\mathrm{E} / \mathrm{A}$ ratio variations derived from $H R$ variation, there seems to be an additional factor to these changes, possibly a reduction in atrial inotropism, as previously shown in animal patterns ${ }^{53}$.

Because of their rich vagal innervation, the atria may have their contractility experimentally reduced by $100 \%$, both by efferent fibers and pharmacological stimulation ${ }^{53}$. Considering that the PYR dose used is well known as sufficient to result in significant AchE activity reduction ${ }^{54}$, one may expect some negative atrial inotropic effects, which could not be measured by the methods used in the present study.

Despite the potential implications of a negative atrial inotropic effect, several studies have shown there is no performance reduction in various situations demanding an increase in cardiac output $(\mathrm{CO})^{48,49,55-57}$. Further studies will be able to validate these findings in populations more dependent on atrial contraction for $\mathrm{CO}$ maintenance, as in patients with ischemic or hypertensive heart disease.

Based on this study, we may infer the following clinical implications: 1) PYR may be considered, with a reasonable safety margin, for future studies in other clinical conditions, such as ischemic heart disease, aiming particularly to analyze its hemodynamic and autonomic effects ${ }^{58}, 2$ ) the PYR effects on HR may be analyzed by other studies, comparing it, for instance, with $\beta$-blockers, in patients with

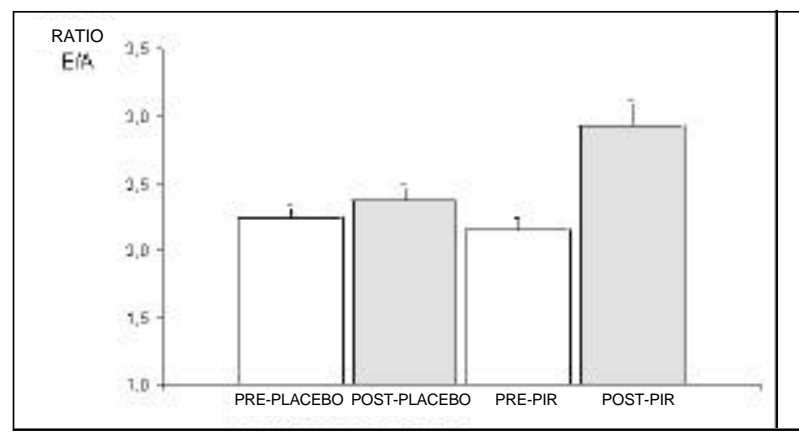

Fig. 5 - Means and standard errors of E/A ratio $\left({ }^{*} \mathrm{p}<0.001\right)$.

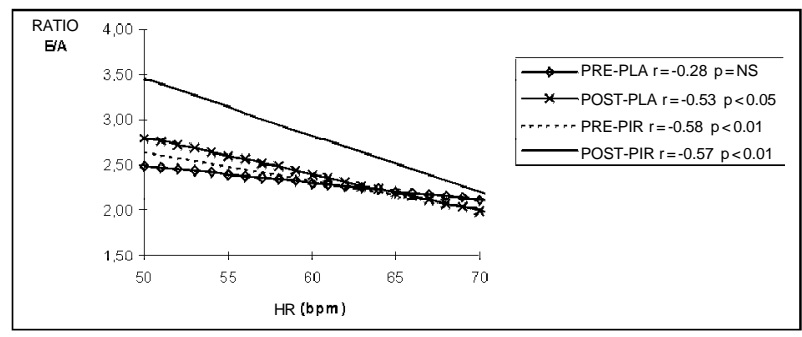

Fig. 6 - Straight lines of regression correlating reduction in heart rate and increase of E/A ratio.

heart failure, since PYR seems to have a smaller negative inotropic effect, 3) assuming that favorable results of the above mentioned considerations will be obtained, one may evaluate the impact of PYR on morbidity and mortality indices in these populations ${ }^{59,60}$.

In conclusion, this study allows us to infer that, in a population of young healthy subjects at rest, in the dose used, PYR is well tolerated and does not change the overall heart pump function. Specifically, PYR does not change BP, does reduce HR, does not change ventricular systolic function, and produces a reduction in A wave, as well as an increase in the E/A ratio.

\section{Acknowledgments}

\section{Support from CNPq and FAPERJ.}

\section{References}

1. Gheorghiade M, Skivkumar K, Schultz L, Jafri S, Tilley B, Goldstein S. Prognostic significance of electrocardiographic persistent ST depression in patients with their first myocardial infarction in the placebo arm of the BetaBlock Heart Attack Trial. Am Heart J 1993; 126: 271-8.

2. Kostis JB, Byington R, Friedman LM, Goldstein S, Furberg C. Prognostic significance of ventricular ectopic activity in survivors of acute myocardial infarction. J Am Coll Cardiol 1987; 10: 231-42.

3. Lichstein E, Morganroth J, Harrist R, Hubble E. Effect of propranolol on ventricular arrhythmia. The beta-blocker heart attack trial experience. Pt 2. Circulation 1983; 67; I5-I10.

4. Webb SW, Afgey AA, Pantridge JF. Autonomic disturbances at onset of acute myocardial infarction, Br Med J 1972; 3: 89-92.

5. La Rovere MT, Mortara A. Assessment of the autonomic nervous system after infarction and its prognostic significance. Cardiology 1994; 39(suppl I): 225-31.

6. Morlet D, Couderc JP, Touboul P, Rubel P. Wavelet analysis of high-resolution ECGs in post-infarction patients: role of basic wavelet and of the analyzed lead. Int J Biomed Comput 1995; 39: 311-25.

7. Schwartz PJ, La Rovere MT, Vanoli E. Autonomic nervous system and sudden cardiac death. Experimental basis and clinical observations for post-myocardial risk stratification. Circulation 1992; 85(suppl): I-77.

8. Turner AW, Malik M. Risk stratification and prediction of sudden death following myocardial infarction. Herz 1995; 20: 200-12.

9. Oser M. Lehofer M, Sedminek A, et al. Heart rate variability as a prognostic tool in cardiology. A contribution to the problem from a theoretical point of view. Circulation 1994; 90: 1078-82. 
10. Puig J, Freitas J, Carvalho MJ, et al. Study of the autonomous nervous system with heart rate spectral analysis in acute myocardial infarction. Rev Port Cardiol 1991; 10: 923-9.

11. Wolf MG, Varigos G, Hunt D. Sinus arrhythmia in acute myocardial infarction. Med J Aust 1978; 2: 52.

12. Billman GE, Schwartz HK, Stone. Baroreceptor reflex control of heart rate: a predictor of sudden cardiac death. Circulation 1982; 66: 874.

13. Keiger RE, Miller JP, Bigger JR. Heart rate variability; a variable predicting mortality following acute myocardial infarction. J Am Coll Cardiol 1984; 3: 547.

14. Levy MN, Schwartz PJ. Vagal control of the heart: Experimental basis and clinical applications. Armonk: Futura Publishing, 1994: 644.

15. Odemuyima OM, Malik T, Farrell. Comparison of the predictive characteristics of heart rate variability index and left ventricular ejection fraction for all-cause mortality, arrhythmic events and sudden death after acute myocardial infarction. Am J Cardiol 68: 434.

16. Casadei B, Pipilis A, Sessa F, Conway J, Sleight P. Low dose of scopolamine increase cardiac vagal tone in acute phase of myocardial infarction. Circulation 1993; 88: 353-7.

17. De Feerrari GM, Mantica M, Vanoli E, Hull SS Jr, Scwartz PJ. Scopolamine increases vagal tone and vagal reflexes in patients after myocardial infarction. $\mathrm{J}$ Am Coll Cardiol 1993; 22: 1327-34.

18. Pedretti R, Colombo E, Braga SS, Carÿ B. Influence of scopolamine on cardiac sympathovagal interaction after acute myocardial infarction. Am J Cardiol 1993; 72: 384-92

19. Vybiral T, Glaeses DH, Morris G, et al. Effect of low-dose transdermal scopolamine on heart rate variability in acute myocardial infarction. J Am Coll Cardiol 1993; 22: 1320-36.

20. Koelle GB. Anticholinesterasic agents. In: Goodman LS, Gilman A - The Pharmacological Basis of Therapeutics. $9^{\text {th }}$ ed. New York: ????, 1996.

21. Yamamoto K, Shimizu M, Ohtani H, Hayashi M, Sawada Y, Iga T. Toxicodynamic analysis of cardiac effects induced by four cholinesterase inhibitors in rats. J Pharm Pharmacol 1996; 48: 935-9.

22. Husain K, Kumar AP, Vijayaraghavan R, Singh R, Das Gupta S. Influence of pretreatment of carbamates on dynamic pulmonary mechanics in rats exposed to sarin aerosols. Indian J. Physiol Pharmacol 1993; 37: 249-51.

23. Leadbeater L, Inns RH, Rylands JM. Treatment of poisoning by soman. Pt 2 . Fundam Appl Toxicol 1985; 5: S225-31.

24. Lee EJ. Pharmacology and toxicology of chemical warfare agents. Ann Acad Med Singapore 1997; 26: 104-7.

25. Volans AP. Sarin: guidelines on management of victims of a nerve gas attack. J Accid Emerg Med 1996; 13: 202-6.

26. Nóbrega ACL, Carvalho ACG, Bastos BG. Resting and reflex heart rate responses during cholinergic stimulation with pyridostigmine in humans. Brazilian J Med Biol Res 1996; 29: 1462-5.

27. Devereux RB, Alonso DR, Lutas EM, et al. Echocardiographic assessment of left ventricular hypertrophy: comparison to necropsy findings. Am J Cardiol 1986; 15: 450-8.

28. Huwez FU, Pringle SD, Macfarlane PW. A comparison of left ventricular mass and volume using different echocardiographic conventions. Int J Cardiol 1991; 30: 103-8.

29. Reichek N. Standardization in the measurement of left ventricular wall mass. Mmode echocardiography. Pt 2. Hypertension 1987; 2: II27-9.

30. Weyman VPA. Left ventricle. I. General considerations of chamber size and function. In: Weyman A - Principle and Practice of Echocardiography. $2^{\text {nd }}$ ed Boston: Lea \& Febiger, 1994: 575-625.

31. Magnin PA, Stewart JA, Myers S. Combined Doppler and phased-array, echocardiographic estimation of cardiac output. Circulation 1981; 63: 388-95.

32. Grossman W, Braunwald E, Mann T, McLaurin LP, Green LH. Contractile state of the left ventrucle in man as evaluated from end-systolic pressure-volume relations. Circulation 1977; 56: 845-52.

33. Marsh JD, Green LH, Wynne J, Cohn PF, Grossman W. Left ventricular endsystolic pressure-dimension and stress-length relations in normal human subjects. Am J Cardiol 1979; 44: 1311-17.

34. Reichek N, Wilson J, Sutton MJ. Noninvasive determination of left ventricular end-systolic stress: validation of the method and initial application. Circulation 1982; 65: 99-108

35. Sagawa K. The end-systolic pressure-volume relation of the ventricle: definition, modification and clinical use. Circulation 1981; 63: 1223-7.
36. Oh JK, Appleton CP, Hatle LK. The nonivasive assessment of left ventricular diastolic function with two dimensional and Doppler echocardiography. J Am Soc Echocardiogr, 1997.

37. Little WC, Ohno M, Kitzman DW, Thoma JD, Cheng CP. Determination of left ventricular chamber stiffness from the time for deceleration of early left ventricular filling. Circulation 1995; 92: 1933-9.

38. Kjekshus JK. Importance of heart rate in determining beta-blocker efficacy in acute and long-term acute myocardial infarction intervention trials. Am J Cardiol 1986; 57: 43F-9F

39. Cohn J, Johnson G, Shabetai R, et al, for the V-HeFT VA Cooperative Studies Group. Ejection fraction, peak exercise oxygen consumption, cardiothoracic ratio, ventricular arrhythmias and plasma norepinephrine as determinants of prognosis in heart failure. Circulation 1993; 87(suppl VI): VI-5-16.

40. Nul DR, Doval HC, Grancelli HO, et al. Heart rate is a marker of amiodarone mortality reduction in severe heart failure. J Am Coll Cardiol 1997; 29: 1199-205.

41. Anderson B, Lomsky M, Waagstein F. The link between acute haemodynamic adrenergic beta-blockade and long-term effects in patients with heart failure. Eur Heart J 1993; 14: 1375-85.

42. Eichorn EJ. The paradox of beta adrenergic blockade for the management of congestive heart failure. Am J Med 1992; 92: 527-38.

43. Cohn JN, Johnson G, Ziesche S, et al. A comparison of enalapril with hydralazine-isosorbide dinitrate in the treatment of chronic congestive heart failure. $\mathrm{N}$ Engl J Med 1991; 325: 303-10.

44. Packer M, Carver JR, Rodeheffer RJ, et al. Effect of oral milrinone on mortality in severe chronic heart failure. N Engl J Med 1991; 325: 1468-75.

45. Waagstein F, Bristow M, Swedberg K, et al, for the Metoprolol in Dilated Cardiomiopathy (MDC) Trial Study Group. Beneficial effects of metoprolol in idiopathic dilated cardiomyopathy. Lancet 1993; 342: 1441-6.

46. Arsura EL, Brunner NG, Namba T, Grob D. Adverse cardiovascular effects of anticholinesterase medications. Am J Med Sci 1987; 293: 18-23.

47. Borland RG, Brennan DH, Nicholson AN, Smith PA. Studies on the possible central and peripheral effects in man of a cholinesterase inhibitor (pyridostigmine). Hum Toxicol 1985; 4: 293-300.

48. Epstein Y, Arnon R, Moran D, Seidman DS, Danon Y. Effect of pyridostigmine on the exercise-heat response of man. Eur J Appl Physiol, 1990; 61: 128-32.

49. Epstein Y, Seidman DS, Moran D, Arnon R, Arad M, Varssano D. Heat-exercise performance of pyridostigmine-treated subjects wearing chemical protective clothing. Aviat Space Environ Med 1990; 61:310-3.

50. Caldwell RW, Lowensohn HS, Chryssanthis MA, Nash CB. Interactions of pyridostigmine with cardiopulmonary systems and their relationships to plasma cholinesterase activity. Fundam Appl Toxicol 1989; 12: 432-41.

51. Arad M, Roth A, Zelinger J, Zivner Z, Rabinowitz B, Atsmon J. Safety of pyridostigmine in hypertensive patients receiving beta blockers. Am J Cardiol 1992; 69: 518-22.

52. Harrison MR, Clifton GD, Pennell AT, DeMaria NA. Effect of heart rate on left ventricular diastolic transmitral flow velocity patterns assessed by Doppler echocardiography in normal subjects. Am J Cardiol 1991; 67: 622

53. Martin P. Atrial inotropic responses to brief vagal stimuli: Frequency-force interactions. Am J Physiol 1980; 239: H333.

54. Ram Z, Molcho M, Danon YL, et al. The effect of pyridostigmine on respiratory function in healthy and asthmatic volunteers. Isr J Med Sci 1991; 27: 664-8.

55. Forster EM, Barber JA, Parker FR Jr, Whinnery JE, Burton RR, Boll P. Effect of pyridostigmine bromide on acceleration tolerance and performance. Aviat Space Environ Med 1994; 65: 110-6.

56. Gawron VJ, Schiflett SG, Miller JC, Slater T, Ball JF. Effects of pyridostigmine bromide on in-flight aircrew performance. Hum Factors 1990; 32: 79-94.

57. Roach JM, Eliasson AH, Phillips YY. The effect of pyridostigmine on bronchial hyperreactivity. Chest 1993; 103: 1755-8.

58. Reis AF, Bastos BG, Mesquita ET, Romêo LJMF, Nóbrega ACL. Disfunção parassimpática, variabilidade da frequêencia cardíaca e estimulação colinérgica após infarto agudo do miocárdio. Arq Bras Cardiol 1998; 70: 193.

59. Pontes PV. Estudo das variáveis hemodinâmicas e da função ventricular sistólica e diastólica com o emprego de piridostigmina (tese de Mestrado). Niterói: Universidade Federal Fluminense, 1997, 55p

60. Pontes PV, Bastos BG, Mesquita ET, Romêo LJMF, Nóbrega ACL. Cholinergic stimulation with pyridostigmine: echocardiographic analysis in healthy subjects. In: III World Congress of Cardiology. Rio de Janeiro, 1998 